\title{
A Sonic Anthropocene. Sound Practices in a Changing Environment (II)
}

\author{
Ivo Louro, Margarida Mendes, Daniel Paiva and Iñigo Sánchez-Fuarros ${ }^{1}$
}

Art and anthropology offer a wide variety of methodological tools and discursive arguments that expand how ecological discourse can be framed in current times. Intervening directly upon the field as a site of direct survey, these disciplines have woven common paths in recent decades, as contemporary artistic practices have become research-based, shifting the position of the creator to an investigative role committed to societal change and the observation of planetary transformations. As such, a plurality of hybrid sonic investigations, like the ones included in this double special issue, now support the current ecological inquiry.

Sound walks and aural modes of perception have shifted during the COVID-19 pandemic, extending our ears from the domestic space towards a tuned down world devoid of planes and traffic, with temporarily expanded bandwidth space. In this sonically and immunologically-woven world, where the privacy of the body has been exhorted to the public arena, communal awareness about the contours of the audiosphere has definitely shifted for a large number of people, as the public/private boundary expanded through both sonic and somatic sensations. This contributed to a renewed sense of corporeality which shapes how we define communities, be they acoustic, political, or remote, woven by a heightened sense of aurality. Now, after this

1 Authors' affiliations: Ivo Louro (Interuniversity Centre for the History of Science and Technology (CIUHCT), NOVA School of Science and Technology, ivomlouro@fct.unl.pt); Margarida Mendes (Centre for Research Architecture, Goldsmiths University of London, mnune001@gold.ac.uk); Daniel Paiva (Centre for Geographical Studies, Institute of Geography and Spatial Planning, Universidade de Lisboa, daniel.paiva@campus.ul.pt); Iñigo Sánchez-Fuarros (Institute of Heritage Sciences (Incipit), Spanish National Research Council (CSIC), inigo.sanchez-fuarros@incipit.csic.es). This work has been supported by various project grants and scholarships from the Portuguese Fundação para a Ciência e a Tecnologia (FCT): "Sounds of Tourism" (PTDC/ART-PER/32417/2017), "Anthropolands" (PTDC/IVCHFC/6789/2014), and "Experiences of synanthropic life in the city" (CEECIND/03528/2018/ UIDP/00295/2020/UIDB/00295/2020/LA/P/0092/2020). 
brief reflexive pause, questions regarding what kind of sonic projects and modes of research we wish to currently support are being debated. How will the post-pandemic sonic reconfiguration proposed by its planetary vibrational halt shape future sonic politics?

Practitioners across the globe have dedicated themselves to documenting and expanding on the impacts of irrevocable sonic thresholds, exploring further how we are enmeshed in cross-scalar ecological relations with the environment and the plural forms of life that inhabit it. Stressing the urge to use sound as a transdisciplinary medium for eco-conscious dialogue, they ask: how can one develop aurally diverse forms of listening that enable expanded modes of awareness that are sensitive to other bodies' aural mechanisms and different forms of wordly cohabitation? And how does this form of sonic awareness motivate the emergence of new tools, methodologies and practices of listening? Although the contributions included in this volume refer to worlds that seem to have gone by, they allow us to imagine potential future scenarios for creative sonic explorations.

This second volume of the "Sonic Anthropocene - Sound Practices in a Changing Environment" special issue continues the inquiry into how sonic research might contribute to current debates about the present environmental crisis, asking how listening practices shape ecological subjects (see Louro, Mendes, Paiva \& Sánchez-Fuarros, 2021). While proposing transdisciplinary forms of eco-literacy and ecosystem analysis, we conjured proposals that debate how sonic tools and aural modes of perception contribute to an attuned sense of eco-social understanding. Such is the purpose of the five proposals that compose this second volume.

Joanna Dobson and Julia Schauerman discuss the role of acousmatic storytelling as a mode of narratively worlding the unpredictable, layered, multi-scalar, and multi-agential threads of the Anthropocene. Taking inspiration from Amitav Gosh's The Great Derangement, they claim that the crisis of the Anthropocene is also a crisis in storytelling. However, they highlight how Gosh fails to recognize the power of sound in the new hybridity of forms he proposes can best tackle climate change and ecological degradation. Acousmatic storytelling consists of such a hybrid form of telling stories combining spoken word, audio recordings from archives and interviews, soundscapes, and music. The authors present and analyze their work Imagined Boundaries to demonstrate how acousmatic storytelling handles other voices and agencies well across space and time. Additional benefits include decentralizing the human both as protagonist and meaning maker, narrating events considered to be beyond representation, and interweaving different perspectives of a story. Some of the imagined boundaries that Dobson and Schauerman transcend here are those identified by Ghosh, like the nature-culture split and the taking of extraordinary events in mainstream literary fiction as unrealistic and, thus, unrelatable to the audience. However, the authors go one step further, pointing out how even Gosh and other authors still assume that non-fiction means fewer creative decisions and composition than fiction. A hurdle, they 
claim, which acousmatic storytelling also proves to be insubstantial. In short, Dobson and Schauerman offer a valuable contribution to this special issue by making an efficient demonstration of the tradition of thought and practice of acousmatic story and a compelling case of how it can be an alluring tool in Anthropocene storytelling.

Carsten Wergin and Edwin Lee Mulligan's contribution proposes a thought-provoking exercise in collaborative reflection on how careful listening to our immediate environment opens up novel ways of thinking about a place. Drawing on Steven Feld's concept of "acoustemology" as a means of inquiry into our experiential knowledge through/with sound, and the notion of "buen vivir", as a counter-hegemonic pulse to the unlimited development embraced by late capitalism, this article demonstrates the power of eco-acoustic ethnographic engagements and storytelling in power struggles for protecting heritage land from resource exploitation. That is the case of the Kimberley region of Northwest Australia, where Indigenous peoples are fighting back against fracking industry pressure. As the authors argue, it is through the kind of eco-acoustic entanglements discussed in the article --where song, dance, Indigenous stories, people and landscapes come together-- that it would be possible to envision hopeful ways of living-well-together in an increasingly uncertain planetary future.

Vishwaveda Joshi and Ira Famarin present the sonic experiments they undertook during the COVID-19 pandemic. Drawing on Robin Nelson's call for challenging the primacy of the written word in academia, Joshi and Famarin explore the possibilities of sounded thinking. They do so through experimenting with two techniques they call Sound Journaling and Sounded Improv, which entail sonic experimentation, aural sharing, and mutual attunement through sound. Their iterative process of a sounded practice-as-research allowed them not only to think beyond the body-mind dichotomy, but also to experience a new praxis of communication and resonance that allowed them to cultivate transindividual solidarity. Joshi and Famarin's experiments are inspirational explorations of how sound can form intimate spacetimes wherein bodily sensations, emotional states and material encounters can be shared and appreciated, even against the backdrop of a suffocating pandemic. Moreover, their experiments hint at the possibilities contained in sound as a method for the exploration of ecological experience.

Pedro Filho discusses the power of what he calls 'entomusic', a neologism that juxtaposes the Ancient Greek word 'entomo' and the modern word 'music'. Entomusic, for Filho, entails all music which is made by, with, or for insects. Arthropods are the largest phylum in the animal kingdom and fundamental for every biome, and yet a large number of its species are among the most threatened. In this sense, Filho's work provides a much-needed aural medium for innovation in insect-human relations. Departing from a reflection on the anthropocentrism of the Anthropocene, the author argues that zoomusicology has a contribution to make toward environmental perception and multispecies relations in the contemporary age. More precisely, drawing his 
own experiments in entomusic, Filho explores how music can be a platform for communication and sharing with insects, and how such aural platform can active a critical and reflexive listening in the context of the Anthropocene.

Guillermo de Llera Blanes provides an audio-textual-visual work on his trek to Everest Base Camp. Mount Everest has become a paradigmatic example of the tragedy of the over exploration of nature, one in which it is human appreciation for geological beauty itself that threatens the stability of geological processes. In his paper, de Llera Blanes re-visits the audio, visual and textual materials produced during his own trek to Everest Base Camp and reflects on his experience by remixing his field materials. Such remixing is accomplished through story-mapping, which allows us to follow de Llera Blanes' footsteps as we listen to the soundscapes he recorded in his journey. This mobile geo-tagged way of listening to soundscapes in a threatened environment presents yet another perspective on the traces that intertwine human activity and environmental change. As he describes the making of his story map, de Llera Blanes' discusses how his own trekking experience was re-signified during this process. In this sense, his paper is an empathic example of how re-composing sounds is always a practice of re-composing the self.

These five essays expand the dialogue started in the first volume of this Special Issue, a dialogue on how to sound the Anthropocene by placing sound at the centre of an interdisciplinary conversation on the challenging planetary transformations we are witnessing. We hope that this is just a beginning and that these two volumes can provide a valuable contribution to the increasingly expanded universe of works that engage with the power of sound in addressing environmental change.

\section{References}

Louro, I., Mendes, M., Paiva, D., and Sánchez-Fuarros, I. 2021. "A Sonic Anthropocene. Sound Practices in a Changing Environment". Cadernos de Arte e Antropologia 10 (1): 3-17. 